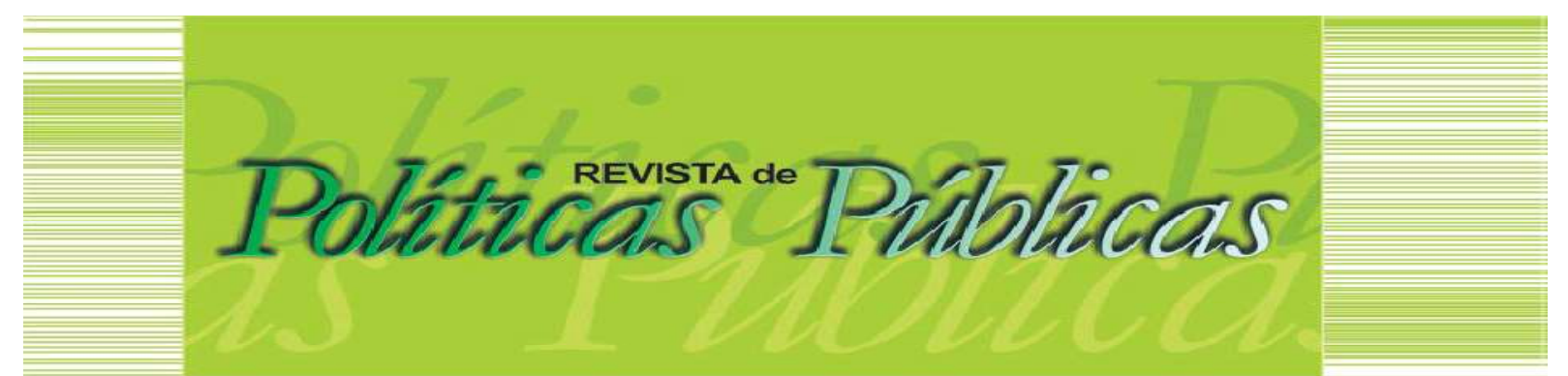

\title{
VIOLÊNCIAS DO ESTADO E SEGURANÇA PÚBLICA EM MOÇAMBIQUE PÓS- INDEPENDÊNCIA
}

\author{
Albino Massimaculo ${ }^{1}$ \\ Dijaci David Oliveira² \\ Telma Ferreira do Nascimento Durães ${ }^{3}$
}

\begin{abstract}
Resumo
Este artigo discute as práticas de violência do Estado em Moçambique. Enfatiza que desde a independência política alcançada em 1975 e posterior constituição do Estado moçambicano, os cidadãos têm questionado sobre o papel deste na segurança pública, assim como na garantia dos direitos humanos já que, em determinados momentos em que as tensões sociais se agudizam, este mesmo Estado, por intermédio da polícia, utiliza a violência como meio para silenciá-las. Parte do pressuposto de que as diferentes práticas de violências e, particularmente, as violências do Estado têm assumido um protagonismo especial e, com ele, o agravamento do sentimento de insegurança pública. Para efetivação deste trabalho, recorreu(-se) a material bibliográfico Por fim, constata que o Estado moçambicano tem utilizado a violência como forma para reprimir essas tensões sociais.
\end{abstract}

Palavras-chave: Moçambique. Segurança pública. Violência de Estado.

\section{VIOLENCE OF THE STATE AND PUBLIC SECURITY IN POST-INDEPENDENCE MOZAMBIQUE}

\section{Abstract}

This article, intends to discuss the practices of State violence in Mozambique. Since the political independence achieved in 1975 and the subsequent constitution of the Mozambican State, citizens have questioned its role in public security, as well as in the guarantee of human rights, since, at certain times when social tensions become more acute, this same State, through the police, uses violence as a means of silencing them. It starts from the assumption that the different practices of violence and, particularly, the violence of the State have assumed a special role and with it the aggravation of the feeling of public insecurity. For the effectiveness of this work, bibliographic material of specialist authors on violence and works on the situation of public security in Mozambique from political independence to the present were used. Finally, it shows that the Mozambican State has used violence as a way to repress these social tensions.

Keywords: Mozambique. Public security. State violence.

Artigo recebido em: 12/12/2018 Aprovado em: 12/09/2019 DOl: http://dx.doi.org/10.18764/2178-2865.v23n2p882-905.

\footnotetext{
1 Licenciado em Ensino de História e Geografia. Doutor em Sociologia pela Universidade Federal de Goiás. Docente da UniRovuma - Universidade de Rovuma, Província de Nampula, Moçambique. Email: amassimaculo@gmail.com

2 Sociólogo. Doutor em Sociologia pela Universidade de Brasília (UnB). Mestre em Sociologia pela Universidade de Brasília (UnB). Docente da Faculdade de Ciências Sociais (FCS) da Universidade Federal de Goiás (UFG). Coordena o Núcleo de Estudos e Pesquisa sobre Criminalidade e Violência (NECRIVI). E-mail: dijaci@gmail.com

${ }^{3}$ Cientista Social. Doutora em Sociologia e Ciência Política pela Universidad Complutense de Madrid (2004). Docente da Faculdade de Ciências Sociais (FCS) e do Programa de Pós-Graduação em Sociologia da Universidade Federal de Goiás (UFG). E-mail: telmamujer1@gmail.com
} 


\section{INTRODUÇÃO}

Com as complexas mudanças no sistema internacional, tanto na esfera econômica quanto política, ocorridas na década de noventa, a hegemonia mundial veio a ser exercida de modo mais evidente pelo mundo ocidental, de tal modo que o capitalismo, com a sua forma mais agressiva, a "neoliberal", passou a constituir um protótipo a ser seguido mesmo para as nações até então recentemente descolonizadas pelos Estados europeus, como é o caso da República de Moçambique1. Evidentemente, os modelos políticos e econômicos exercem uma influência considerável sobre as estruturas sociais, sobre políticas públicas a serem adotadas pelos governantes e, consequentemente, sobre a vida social. Assim, a escolha desse tema permite realizar uma discussão que pode contribuir para as reflexões sobre o processo de democratização em Moçambique.

Por conseguinte, o objetivo deste artigo será discutir o problema da violência e da segurança pública em Moçambique. Como foco temporal, trabalharemos com dados a partir das mudanças políticas ocorridas após os eventos da queda do Muro de Berlim, portanto, desde 1990.

O nosso pressuposto é que nos países que seguem as orientações neoliberais (mas que não se colocam claramente como neoliberais), como é o caso de Moçambique, as práticas de violências, e particularmente as violências efetivadas pelo Estado, têm assumido um protagonismo especial e, com ele, o agravamento da insegurança pública. Portanto, partimos da hipótese de que 0 Estado moçambicano tendo uma orientação neoliberal e não se colocando claramente como tal, em determinados momentos em que as tensões sociais se agudizam, em vez de implementar políticas públicas de enfrentamento da desigualdade, utiliza as instituições de segurança e suas práticas violentas como meio de assegurar o controle social e estabelecer o que chamam de "ordem" e "tranquilidade públicas".

Deve-se deixar claro que o estado também tem atuado por meio de elaboração de políticas públicas. Contudo, dada a tradição política autoritária que sempre caracterizou a governação do País desde o período colonial até aos dias de hoje (BRITO et al 2017) poucas são iniciativas governamentais para elaboração de políticas públicas de redução das desigualdades sociais (principal razão para as revoltas populares). No entanto, devido ao aumento desses eventos, o governo tem tomado medidas esporádicas que muitas vezes caem em descrédito em virtude de não trazerem resultados satisfatórios e esperados pela maioria da população moçambicana. Brito et al (2017) apontam algumas iniciativas que acabaram fracassando devido às dificuldades financeiras no orçamento geral do Estado: a) subsídio aos operadores de transporte públicos urbanos; interurbanos e interprovinciais com vista a superação das taxas de combustíveis (aqui foi introduzido o Programa de Subsídio aos Transportes de Passageiros -PSTP) que não passou apenas de uma intenção; b) 


\section{VIOLÊNCIAS DO ESTADO E SEGURANÇA PÚBLICA EM MOÇAMBIQUE PÓS-INDEPENDÊNCIA}

Subsídio de cesta básica para população carenciada que nem chegou a funcionar; c) Expansão do fundo de Desenvolvimento Distrital (FDD) para os distritos urbanos (devido ao não retorno dos fundos, o programa perdeu sustentabilidade); d) Redução das taxas aduaneiras de importação de arroz da terceira qualidade e açúcar; e) Subsídio aos panificadores; f) Plano de Ação para Produção de Alimentos (PAPA) que tinha objetivo de reforçar a produção alimentar no país, todavia essa produção alimentar se manteve inalterada ao longo dos anos precedentes; g) Programa Estratégico para a Redução da Pobreza Urbana (PERPU) de 2010-2014. Evidentemente cada um desses programas mereceria uma análise específica. Contudo, a ineficiência deles acabou concorrendo para as revoltas populares que abordaremos mais a frente.

Para a consecução deste estudo, tomamos como suporte o material bibliográfico de autores especialistas sobre a violência e alguns trabalhos que discutem o tema da segurança pública em geral e, particularmente, em Moçambique desde a independência até a atualidade, assim como Relatórios da Liga Moçambicana dos Direitos Humanos.

Com este material, objetivamos compreender algumas correntes analíticas que procuram explicar o problema da violência no mundo contemporâneo, sobretudo a violência de Estado, objeto deste estudo, e sua relação com a insegurança pública em Moçambique. Na pesquisa documental, recorremos às Constituições que marcaram a história de Moçambique pós-independente (de 1975, de 1990 e a de 2004). A análise e a intrepretação das duas últimas Constituições têm como propósito compreender os eventuais distanciamentos entre as práticas do cotidiano policial e a legislação do País.

\section{DISCURSO DEMOCRÁTICO E O MONOPÓLIO DO USO DA FORÇA}

Nesta parte do artigo procuraremos discutir conceitualmente o que chamamos de violência. $\mathrm{O}$ objetivo será delimitarmos suas dimensões, compreender mais sobre sua complexidade e abrangência. Contudo, tentaremos propor uma concepção mais operacional que nos permita analisar a prática da violência; os dados estatísticos; e as políticas públicas de seguranças implementadas pelo Estado de Moçambique.

Alguns autores, como Pimenta (1996, p. 18), reconhecem que o termo "violência" pode assumir vários aspectos e formas. Assim, nos seus estudos, esse autor privilegia aquela violência "[...] do sangue, da carne, ou seja, a violência explícita de forma - não só sentida como também praticadasofrida no dia-a-dia". Portanto, para Pimenta (1996), a violência se traduz por meio de uma agressão física direta sobre o corpo da pessoa. Para além dessa perspectiva, autoras como Duarte e Silva (2004) reconhecem que a violência como problema social não se restringe simplesmente ao emprego 
da violência física, já que verbalmente e sem o recurso da força também se percebem práticas de violência. Exemplo evidente são os diferentes tipos de preconceito e as diversas formas de discriminação.

Seja na forma de agressões físicas, seja como práticas subjetivas, a violência é um problema social e remonta aos primórdios da humanidade (Alissio, 2007). Ao longo da história, o surgimento do Estado (ou de estruturas de poder mais centralizadas) permitiu que houvesse um acúmulo de uso da força. Isto é, apenas os agentes autorizados do Estado (governantes, juízes, polícia) poderiam fazer uso da violência (utilizar armas, punir, aprisionar, conduzir à força etc). Assim descreve Weber:

\footnotetext{
O Estado, do mesmo modo que as associações políticas historicamente precedentes, é uma relação de dominação de homens sobre homens, apoiada no meio de coação legítima [...]. Para que ele subsista, as pessoas dominadas têm que se submeter à autoridade invocada pelas que dominam no dado momento $(1999$, p. 526).
}

Pelas palavras do autor, percebe-se que todos os Estados, desde os mais autocráticos, passando aos mais neoliberais, ostentam o monopólio do uso legítimo da força na medida em que agem em defesa das suas soberanias ou sobre as práticas sociais. A despeito desta prerrogativa dos Estados, as práticas cotidianas de uso da violência pelos indivíduos, ou mesmo as práticas abusivas empreendidas pelos agentes do Estado, demonstram que a violência não está contida. Santos (2009) chama a atenção para o fato de que muitas práticas de violência no tecido social são resultado do uso excessivo de poder. Logo, enfrentar tais problemas requereria a constituição de mecanismos de avaliação das políticas de segurança, e no caso da violência do Estado, de mecanismos de controle externos.

Ainda pensando sobre a delimitação conceitual de poder, Offe (1972, p. 146) destaca que "[...] só tem sentido em um sistema social quando for considerado como uma categoria relacional, como uma relação complementar entre dois elementos": Para o autor, é necessária uma autorização, concedida de acordo com a própria estrutura do sistema social, para o exercício do poder entre dois elementos. Fora deste contexto prevalece a "violência física direta" (p.146).

Segundo o autor, o Estado capitalista requer ao mesmo tempo "praticar e tornar invisível o seu caráter de classe" (OFFE, 1972, 163). Ao ocultar seu caráter classista e se apresentar sob a aparência de neutralidade de classe, o Estado capitalista estabelece as condições estruturais necessárias para exercer a dominação de classe e, portanto, seu projeto político. Nesta perspectiva, 0 Estado e as instituições políticas se constituem a partir de uma seletividade estrutural do sistema social, que viabiliza diferentes tipos de violências a determinados grupos sociais.

Em particular, no caso das violências do Estado em Moçambique, conjecturamos que quem não possui o poder são as classes desfavorecidas ou os segmentos subalternos, como diria 
Spivak (2010). Estes estão sujeitos às diversas injustiças do capitalismo neoliberal. São esses segmentos sociais, em geral das classes mais despossuídas dos bens necessários à vida que, exigindo seus direitos, são repelidos por meio de fortes aparatos militares, o que coloca em causa 0 direito à manifestação plasmado na Constituição da República e a segurança pública. Procurando explicar a essência do neoliberalismo no mundo, Wacquant (2012, p.14) considera tratar-se de:

[...] um projeto político transnacional que visa refazer o nexo entre mercado, estado e cidadania a partir de cima. Esse projeto é levado adiante por uma nova classe dirigente global em formação, composta pelos presidentes e executivos séniores das firmas transnacionais, políticos influentes, administradores estatais e altos funcionários de organizações multinacionais [...].

Esse novo regime capitalista, orientado nessas três dimensões e ligado à difusão de políticas punitivas (domínio da assistência social e criminal), articula-se em quatro lógicas institucionais, a saber: (i) a desregulamentação econômica; (ii) delegação, retração e recomposição do estado do bem-estar; (iii) um aparato penal em expansão, evasivo e proativo e, finalmente, (iv) a alegoria cultural da responsabilidade individual (WACQUANT, 2012).

Assim, o neoliberalismo, assente em tais lógicas institucionais, sufoca constantemente as classes mais pobres, empurrando-as para condições mais degradantes da vida social. Em contrapartida, as classes que ocupam posições de prestígio na estrutura social vivem de luxo e onstentações. Por conseguinte, Brito (2012) observa que em Moçambique a pobreza vem aumentando consideravelmente desde 2002. Apesar de as províncias de Niassa, Tete, Cabo Delgado, Inhambane e Maputo Cidade apresentarem uma tendência de crescimento populacional, as províncias de Nampula, Zambézia, Sofala, Manica, Gaza e Maputo Província apresentam uma linha de crescimento negativa (BRITO, 2012). O quadro que se segue apresenta essa evolução da população pobre por província com tendências negativa e positiva no período 1997-2009.

Tabela 1 - Evolução da população pobre por província com tendências negativa e positiva no período 1997-2009

\begin{tabular}{|c|c|c|c|c|}
\hline Províncias & 1997 & 2002 & 2009 & 2002-2009 \\
\hline \multicolumn{5}{|c|}{ Tendência Positiva } \\
\hline Nampula & 2.110 .714 & 1.793 .660 & 2.352 .647 & 558.987 \\
\hline Zambézia & 2.108 .650 & 1.550 .296 & 2.891 .910 & 1.341 .614 \\
\hline Sofala & 1.203 .063 & 547.276 & 1.026 .020 & 478.744 \\
\hline Manica & 650.703 & 526.252 & 854.601 & 328.349 \\
\hline Gaza & 721.521 & 760.866 & 798.121 & 37.259 \\
\hline
\end{tabular}




\begin{tabular}{l|r|r|r|r}
\hline Maputo Província & 545.075 & 695.772 & 897.075 & 201.303 \\
\hline \multicolumn{5}{|c|}{ Tendência Negativa } \\
\hline Cabo Delgado & 792.236 & 964.432 & 635.052 & -329.380 \\
\hline Niassa & 570.853 & 477.757 & 417.757 & -60.186 \\
\hline Tete & 1.009 .001 & 830.024 & 825.720 & -4.304 \\
\hline Inhambane & 955.832 & 1.070 .889 & 783.966 & -286.923 \\
\hline Maputo Cidade & 472.238 & 560.120 & 414.490 & -145.630 \\
\hline Total Geral & 11.139 .885 & 9.777 .344 & 11.897 .177 & $\mathbf{2 . 1 1 9 . 8 3 3}$ \\
\hline
\end{tabular}

Fonte: Institudo Nacional de Estística e Direção Nacional de Estudos e Análises Políticas (2010) citados por Brito (2012).

Em Moçambique, a opção do Estado pela política neoliberal a partir da segunda metade dos anos de 1980 e início da década de 1990 começa com a adesão às Instituições de Bretton Woods (Banco Mundial e Fundo Monetário Internacional), a liberalização da economia e a implementação de planos de recuperação econômica². A respeito da ação das instituições de Bretton Woods, Abrahamsson e Nilsson (1994, p.287) afirmam:

O Programa de ajustamento estrutural formulado pelas instituições de Bretton Woods procura, através da liberalização do comércio e da desvalorização da moeda, estimular um aumento de exportação. Na sequência da baixa de preços de bens de exportação tradicionais no mercado mundial, foram tomadas medidas especiais para aumentar a exportação dos produtos de exportação não-tradicionais.

No entanto, segundo Brito et al. $(2015,2015$, p.7), é importante ter a seguinte compreensão:

[...] a partir dos anos de 1990, a política de liberalização econômica que se tinha iniciado em meados dos anos 1980, mas que não tinha praticamente tido efeitos significativos dada a situação de guerra, foi retomada. A liberalização dos preços, a privatização da maior parte das empresas estatais e a procura de investimento estrangeiro iniciada nos anos 1990, acompanhada pela oferta de incentivos fiscais, viriam alguns anos depois a traduzir-se no surgimento de megaprojetos, maioritariamente ligados à prospeção e exploração de recursos naturais (principalmente gás, carvão, areias pesadas e petróleo).

Relativamente à segurança pública, Calveiro (2012, p. 171) entende que se trata do "[...] conjunto de políticas que procuram garantir uma determinada ordem mediante a prevenção e repressão do que dentro de um sistema hegemônico em particular se consideram delitos e crimes". Tomando como referência a Constituição da República de Moçambique de 1990, Art. 254, n. 1 , constata-se que está consoante com esta definição:

A Polícia da República de Moçambique, em colaboração com outras instituições do Estado, tem como função garantir a lei e a ordem, salvaguarda da segurança de pessoas e bens, 
tranquilidade pública, o respeito pelo Estado de Direito Democrático e a observância estrita dos direitos e liberdades fundamentais dos cidadãos (MOÇAMBIQUE, 1990).

No entanto, o direito à manifestação, que muitas vezes é reprimida, é expresso no Art. 51, preconizando que "todos os cidadãos têm o direito à liberdade de reunião e de manifestação nos termos da lei" (MOÇAMBIQUE, 1990).

Assim, em consequência de crescente custo de vida, as manifestações populares que tiveram lugar nas principais cidades de Moçambique, com maior ênfase na capital (Maputo), nos anos de 1993, 2008, 2010 e 2012, tal como descreve Chaimite (2014, p.92) foram seguidas de repressão já que:

\begin{abstract}
A atuação da polícia, que esteve sempre em consonância com a "linha dura" adotada e expressa publicamente nos discursos das autoridades governamentais, teve as suas consequências: se em 1993 morreu uma pessoa e mais de cinquenta ficaram feridas, em 2008 morreram pelo menos três (3) pessoas e o número de feridos ultrapassou as duas centenas. Em 2010, mais de uma dezena de pessoas perderam a vida nas manifestações e o número de feridos, entre graves e ligeiros, foi superior a quinhentos (500).
\end{abstract}

Na verdade, como referiu Humbane (2016, p.179), nota-se aqui o uso da força fora dos limites da legalidade, uma vez que "a polícia tem sido acusada de graves práticas abusivas dos direitos humanos [...]".

Cabe-nos, ainda que brevemente, falar mais sobre esse braço armado do estado, a polícia. $O$ processo de constituição da corporação policial como instituição está intimamente ligado à proclamação de independência nacional em 1975 e a constituição do Estado moçambicano (BORGES, 2012).

Sobre a gênese da polícia moçambicana, Tsucana (2014) fala que tudo tem seu início com a materialização da cláusula 11 dos acordos de Lusaka (Decreto - Lei n 54/75, de 17 de maio de 1975) que autorizou a criação do Corpo de Polícia de Moçambique (CPM) que, inicialmente, era formado pelos antigos guerrilheiros da Frente de Libertação de Moçambique (FRELIMO) e, sem formação policial, substituiram a polícia colonial.

Como corolário da evolução política de Moçambique pós-independente, a polícia teve três designações distintas: Corpo de Polícia de Moçambique - CPM, Polícia Popular de Moçambique PPM e Polícia da República de Moçambique - PRM (TSUCANA, 2014). Tomando em consideração o regime presidencialista que foi adotado, o Presidente da República é o comandante em chefe de todas as forças de defesa e segurança do País, incluindo a Polícia. Inicialmente, a Polícia de Segurança Pública Portuguesa (PSP) desempenhou um papel fulcral na transmissão do conhecimento e das práticas operacionais, assim como nos procedimentos jurídico-administrativos aos novos policiais do Estado ora instituído (BORGES, 2012). 
Em termos de estrutura organizacional (TSUCANA, 2014), a Polícia de Moçambique é constituída por quatro ramos e seis Unidades de atuação. (1) Ramos: Polícia de Segurança Pública; Polícia de Investigação Criminal; Polícia de Fronteira; Polícia Costeira Fluvial e Lacustre. (2) Unidade de atuação: Unidade de Intervenção Rápida; Unidade de Desativação de Engenhos Explosivos; Unidade de Proteção de Altas Individualidades; Unidade de Cavalaria; Unidade de Operações de Combate ao Terrorismo e de Resgate de Reféns; Unidade Canina.

Como se deve constatar, na ocorrência de uma manifestação popular, o ramo responsável para garantia da segurança pública é o da Polícia de Segurança Pública que, em casos extremos, pode ser apoiada pelas Unidades de Intervenção Rápida ou Canina. Para além do Presidente que é comandante em chefe, a hierarquia da Polícia conta com o Ministro do Interior e do Comandante Geral da Polícia. Partindo do Comando geral da Polícia que funciona na capital do País-Maputo, a extensão da corporação faz-se através dos Comandos Provinciais e Distritais, mas com forte obediência ao Comando geral e ao Ministério de Interior. Não existindo polícia estadual, toda corporação policial é de carácter nacional e cada membro pode tabalhar em qualquer parte do território nacional.

Note-se que durante muito tempo, mesmo com a democratização do País, o ingresso para corporação policial em última instância era ditado, entre outros aspectos, pela militância partidária e a disciplina político-militar (BORGES, 2014).

Enfim, ao longo desta parte observamos que o modelo de Estado protetor que possui o controle legítimo da violência, conforme destacou Weber (1999), existe apenas como referencial. $\mathrm{Na}$ prática social a violência está disseminada como problema social, vivenciado por grande parte da sociedade moçambicana, já que é visível a perda de controle do Estado sobre seus próprios agentes que, por obrigação da lei, deveriam salvaguardar a segurança dos cidadãos.

Exemplos do que acabamos de referir são casos de proliferação de armas de fogo no seio das comunidades3; a expropriação das terras dos camponeses pelas empresas multinacionais de exploração mineira que, segundo Matos e Medeiros (2012), as comunidades são compulsivamente retiradas dos seus campos de cultivo para locais distantes afetando de certo modo o seu ethos e uso excessivo da força para silenciar manifestações sociais (BERTELSEN, 2017). Assim, com o advento da ordem neoliberal, o Estado tem se tornado um forte produtor de novas práticas de violência, ao implementar formas de enfrentamento e de silenciamento das manifestações sociais que demonstram insatisfação em relação às políticas sociais adotadas pelos governantes 4 .

Desse modo, o Estado tem se tornado mais repressor, sobretudo quando não é capaz de resolver os problemas da desigualdade, da fome e da pobreza que são muitas vezes o móbil das manifestações populares (CHAIMITE, 2014). E, para evitar essas manifestações que desafiam o status quo, as agências estatais de vigilância e controle social " [...] quando em situações de confronto" agem 
com muita virulência contra as pessoas indefesas (LALÁ; OSTHEIMER, 2004, p.23). Neste sentido, é sintomático Fernández (2017, p.184) considerar que, "trata-se [...] de um estado republicano moderno quanto à estrutura e funcionamento, que na sua acepção estatista concentra e reivindica de maneira insistente, seu monopólio de propriedade e a violência sobre os corpos dos seus cidadãos". É esta última atuação que veremos na parte subsequente.

\section{VIOLÊNCIA DO ESTADO E SEGURANÇA PÚBLICA EM MOÇAMBIQUE NO PERÍODO PÓS- INDEPENDÊNCIA}

Moçambique foi colônia portuguesa e tornou-se politicamente independente apenas em 1975, após a vitória da Frente de Libertação de Moçambique (FRELIMO). Lalá e Ostheimer (2004) observaram que, com essa independência em Moçambique,

[...] foi adotada uma constituição, a qual definia o papel da FRELIMO como força de liderança do Estado e da sociedade, bem como assegurava a legitimação do regime de partido único, eliminando, deste modo, qualquer forma de pluralismo social. (LALÁ; OSTHEIMER, 2004, p. 4)

De fato, depois da proclamação da independência, a FRELIMO, como partido único e com uma orientação de recorte socialista, implantou um regime ditatorial e vedou as principais liberdades democráticas, tendo feito prisioneiros todos políticos que se opunham à sua ideologia e, além disso, empurrou o país numa governação autocrática que se prolongou até a promulgação da segunda Constituição em 1990. Esta Constituição abriu caminho para a realização do Acordo Geral de Paz em $1992^{5}$ e das primeiras eleições multipartidárias em 1994. A esta fase que se seguiu depois da Independência, o Estado moçambicano contou principalmente com o apoio dos países socialistas na época (União das Repúblicas Socialistas Soviéticas - URSS; Alemanha Oriental; Cuba e China Popular).

A despeito do apoio dos países socialistas, a Constituição da República promulgada às vésperas da independência (MOÇAMBIQUE, 1975), no Art. 22, definia que "a República Popular de Moçambique consolida e desenvolve a solidariedade com os países socialistas, seus aliados naturais, solidariedade forjada na luta pela independência nacional".

Por razões estritamente metodológicas, declinamos aqui de incluir quaisquer dados sobre a violência do Estado português na então colônia de Moçambique, já que pretendemos discutir neste artigo o problema das violências do Estado e da segurança pública nos países de orientação neoliberal, mais especificamente sobre as violências do Estado em Moçambique pós-independência. Queremos recordar que o termo "violências do Estado" pode ser compreendido sob duas perspectivas: 
primeiramente, aquela que é feita entre diversos Estados (guerras e confrontos internacionais), seja exercida por Estado ou por grupos políticos e religiosos e, em seguida, as violências exercidas internamente pelo Estado no âmbito de Estado-Nação (violências policiais, militares entre outros órgãos do Estado) (SANTOS, 2009).

No caso vertente, o nosso enfoque direciona-se na perspectiva de violências do Estado em nível interno, portanto, no âmbito de Estado-Nação moçambicano. Por conseguinte, para compreender as violências do Estado em Moçambique pós-independência, dividiremos este período histórico em dois momentos distintos: 1975 a 1990; 1990 à atualidade.

O período de 1975 a 1990 compreende a proclamação da independência política e a implantação do Estado moçambicano. Nesse período foi instaurada uma ditadura de partido único, fato que provocou indignação daqueles que tinham uma visão política e ideológica diferente do partido FRELIMO. Em consequência dessa divergência, o país ficou mergulhado em um conflito armado que só terminou com os Acordos de Roma em 1992. Durante esse período os opositores do governo eram perseguidos e feitos prisioneiros.

O período de 1990 à atualidade abarca a promulgação da Constituição multipartidária de 1990, abrindo espaço para início do processo de democratização do país, e paralelamente às conversações de paz, em que o governo avançou continuamente com a liberalização política do país (LALÁ; OSTHEIMER, 2004).

Administrativamente, o atual território de Moçambique, que se constituiu como um País fruto da acessão da independência em 1975, está divido em 11 Províncias a saber: a) Zona Sul: Maputo cidade, Maputo província, Gaza e Inhambane; b) Zona Central: Sofala, Manica, Tete e Zambézia; c) Zona Norte: Nampula, Cabo Delgado e Niassa.

Cada Província é constituída por Distritos e estes por sua vez em Postos Administrativos. O substrato mais ínfimo desta divisão administrativa é composta pelas localidades. Apesar de existir centralização dos órgãos decisórios na vida política do País, nos últimos anos, o Parlamento moçambicano aprovou um pacote legislativo que cria governos locais. 0 destaque desta autonomização vai para as cidades e algumas vilas.

É importante referir que Moçambique, de ponto de vista cultural, apresenta várias facetas, ou seja, é um mosaico constituído por vários grupos etnolinguísticos, cada um com a sua própria organização social e práticas culturais (SAMB, 2016). No entanto, apesar de Moçambique viver atualmente em um ambiente de democracia multipartidária, ainda persistem tensões políticas que não raras vezes empurram o país para novas guerras fratricidas, como a dado momento observaram Eusébio e Magalhães (2016, p.1) que: 
0 ano de 2013 entrou [...] para o lado obscuro da história de Moçambique: a tensão política que era evidente no campo do discurso - através da política de acusações entre os atores políticos na arena pública - transforma-se numa "tensão político-militar" envolvendo 0 governo de Moçambique, liderado pela partido Frelimo, e o partido Renamo, dois protagonistas da guerra civil que teve o seu "fim" no ano de $1992 \mathrm{com}$ a assinanatura, em Roma, do Acordo Geral de Paz (AGP).

Muito longe de se praticar o modelo agonístico de democracia defendido pela pósmarxista Mouffe (2005), as autoridades governamentais moçambicanas sempre trataram como inimigos os seus opositores políticos, relegando aquilo que a autora considera relevante na esfera de convivência pluralista atual: "[...] construir o 'eles' que são os seus opositores, de tal modo que não sejam percebidos como inimigos a serem destruídos, mas como adversários, ou seja, pessoas cujas ideias são combatidas, mas cujo direito de defender tais ideias não é colocado em questão" (MOUFFE, 2005, p. 20, grifos nossos).

A partir de crítica à teoria política dominante a autora propõe um modelo alternativo de democracia denominado por ela de "pluralismo agonístico". A tarefa primordial da política democrática, nesta perspectiva, é deslindar a impossibilidade do consenso racional defendido como forma ideal do exercício da democracia. Assentadas em bases racionalistas, individualistas e universalistas abstratas a abordagem dominante na teoria democrática liberal pressupõe a eliminação do poder e do antagonismo na esfera pública mediante deliberação e discussão racional. Mouffe assevera a existência de duas formas de relações políticas: antagonismo entre inimigos e agonismo entre adversários. Defendendo a segunda, argumenta que o antagonismo sempre existiu na história das sociedades humanas, todavia é necessário, em uma democracia, transformar o antagonismo em pluralismo agonístico, ou seja, perceber os grupos sociais diferentes e dissidentes como adversário não como inimigos a serem exterminados - e que, desde os princípios ético-políticos da democracia, a manifestação de seus interesses sejam oportunizadas (MOUFFE, 2005).

Voltado para o plano político de Moçambique, outro aspecto não menos importante é a elevação constante de custo de vida, o que provoca a agudização das tensões sociais. Assim, um estudo realizado pelo Centro de Integridade Pública (CIP) 6 em 2016 constatou que o país enfrenta atualmente uma crise econômica jamais vista desde a assinatura do Acordo Geral de Paz em Roma em 1992, caracterizada por: baixos preços de matérias-primas destinadas à exportação, com ênfase aos produtos como gás, alumínio e carvão térmico; redução da ajuda externa ao já deficiente orçamento do Estado; depreciação da moeda nacional (Metical) relativamente à moeda rand da vizinha África do Sul e ao dólar americano; redução significativa do investimento externo direto (de aproximadamente 40\% em 2013 para até menos de 30\% do PIB em 2015); dificuldades na cobrança de impostos, em virtude de diferentes fatores, como o peso da economia informal, a evasão fiscal e a generalização da crise econômica pelo país adentro (Moçambique, 2016). 
Por sua vez, o Estado, por intermédio da polícia e ignorando políticas públicas eficazes que minimizariam problemas da população desfavorecida, utiliza a violência como meio para silenciar essas tensões sociais. Sobre esse caráter violento do Estado moçambicano, Chaimite $(2014$, p.86) destaca que:

[...] a forte repressão que se verifica durante as manifestações em Moçambique, associada à partidarização do aparelho do Estado, à concentração do poder e bipartidarização do cenário político, são alguns dos elementos que contribuem para a descrição da estrutura de oportunidades políticas do país como sendo tendencionalmente fechada.

Assim, o autor termina enfatizando que:

[...] esta tendência desenvolve-se, sobretudo, no período imediatamente posterior à independência do país, em 1975, pois foi neste período que, a partir da tradição política autoritária de partido único, se estabeleceram as bases iniciais do controlo político e social que até hoje dificultam tanto a estruturação de movimentos representativos independentes como a organização de manifestações. (CHAIMITE, 2014, p. 86).

Sobre a agudização de tensões em consequência da elevação constante do custo de vida,

Brito et al $(2015$, p.27) constataram que:

[...] desde 2007, Moçambique viveu vários episódios explosivos de mobilização popular (2008, 2010 e 2012) em que os fatores de revolta têm sido, juntamente com o custo de transporte, o sentimento de desigualdade crescente e a cada vez mais visível corrupção, os aumentos dos preços dos alimentos. Embora se tenham espalhado, com menor intensidade, para outras cidades, o berço e o palco principal dos protestos foi o grande Maputo, uma área metropolitana abrangendo a capital, Maputo, e a cidade satélite da Matola [...].

Estando numa era de avançadas tecnologias de comunicação, o recurso de mensagens SMS (Short Message Service) foi uma alternativa viável usada pela população para disseminar informações relativas às manifestações populares. Contudo, sobre essa estratégia comunicativa em períodos de tensão social e em consequência da ausência de movimentos sociais com fortes tradições de luta,

Os protestos populares tiveram sempre uma origem anônima. Com efeito, a mobilização foi feita através de mensagens sms que circulavam de forma viral nas redes de telefonia móvel e nas redes sociais (Facebook), meios de comunicação e de expressão em rápido desenvolvimento no país, que abrangem praticamente todas as camadas sociais (particularmente o acesso aos sms) e cuja natureza torna o seu controle difícil por parte do governo (BRITO e al, 2015, p. 30).

Observando a violência protagonizada pela polícia em Moçambique, Duma (2008) admite que "o público tem mais medo da polícia que dos criminosos" e descreve:

Desde o final da guerra civil em 1992, foram tomadas diversas medidas para melhorar 0 funcionamento e a conduta da polícia. Estas medidas incluem um projeto de formação coordenado pelo Programa das Nações Unidas para o Desenvolvimento (PNUD) (1997 e 2004), a adopção de um Plano Estratégico em 2004, que enfatizou a proteção crescente dos direitos humanos e a integração dos direitos humanos no currículo de formação da polícia. 
Contudo, essas medidas não são eficazes até a policia ser responsabilizada pelas suas ações.

A não responsabilização pelas violações dos direitos humanos não só implanta a impunidade no seio da polícia como envia também a mensagem de que os métodos policiais que violam os direitos humanos são aceitáveis. (DUMA, 2008, p. 3-4).

Sobre a desconfiança da população em relação à atuação da polícia, Frattari (2011, p.105) argumenta:

O medo da polícia, que se soma à deslegitimação do Poder Judiciário, impõe severos obstáculos ao controle da violência e compromete a democracia, uma vez que os indivíduos tendem a buscar meios privados (muitas vezes ilegais), para lidar com [...] as ameaças. Disto resulta um círculo vicioso que só pode ter como resultado o aumento da violência, lembrando o velho ditado que a violência gera outra violência.

No entanto, é importante compreender que, apesar de as greves registradas em Moçambique nos anos de 2008, 2010 e 2012 terem sido parte integrante de um movimento de dimensão mais globalizada, resultante de aumento constante dos preços dos produtos alimentícios em nível mundial, elas foram particularmente o reflexo da situação econômica do país e surgiram como consequência da exclusão social e política de alguns grupos sociais do meio urbano mais desfavorecidos no país (BRITO et al., 2015).

Lembremos que as violências do Estado podem assumir várias formas, desde as agressões, desaparecimentos forçados, perseguições, torturas e até mesmo mortes, sendo que os seus praticantes podem ser os policiais e/ou militares e outros agentes, havendo em todos esses casos um denominador comum - a coabitação da violência legítima com a violência ilegítima (BARBOSA, 2013). O referido autor chama a atenção:

Nesse processo de legitimação da violência se o Estado cria e implementa as leis ao serviço
da justiça, então a violência utilizada no exercício da mesma será, também ela, tida como
justa porque serve os interesses da sociedade. Quando a natureza ilegítima dos atos é posta
em evidência a segurança nacional surge, por norma, como último grande recurso de
legitimação (BARBOSA, 2013, p. 14).

Num exemplo claro de violências do Estado em Moçambique, o trabalho de Lalá e Ostheimer (2004, p. 23) indica a morte por asfixia de 119 reclusos em novembro de 2000, encarcerados numa cela de $21 \mathrm{~m}^{2}$ em Montepuez, província de Cabo Delgado, que, segundo esses autores, "[...] deixam transparecer a negligência 'por defeito' dos direitos humanos no País e a fragilidade do Estado de Direito".

A crescente implantação de megaprojetos de exploração de recursos naturais ${ }^{7}$ que expropriam espaços de pequenos agricultores, deixando-os na condição de reassentados em terrenos inóspitos, tem provocado protestos que também são silenciados pela polícia por meio do uso excessivo de armas letais e não letais. Como consequência dessa política de reassentamentos, Mutzenberg (2014) considera que há confrontos visíveis e tensões latentes, uma vez que, no caso concreto da 
empresa multinacional brasileira Vale do Rio Doce, na cidade de Moatize, província de Tete, frequentemente assiste-se a contestações populares que são silenciadas pela força das armas. No quadro que se segue, indicamos algumas regiões onde foram ou são implantados megaprojetos que constituem fortes incubadoras de tensões que podem culminar ou culminaram com manifestações populares.

Quadro 1- Algumas regiões cujos megaprojetos constituem incubadoras de tensões sociais

\begin{tabular}{|c|c|c|}
\hline Região de implantação & Tipo de megaprojeto & Atores em confronto \\
\hline Maputo - Katembe & Megaprojeto de construção da ponte & $\begin{array}{l}\text { População reassentada versus } \\
\text { autoridades governamentais }\end{array}$ \\
\hline Moatize - Tete & $\begin{array}{l}\text { Megaprojeto de extração de carvão } \\
\text { mineral da empresa multinacional } \\
\text { Vale-Moçambique }\end{array}$ & $\begin{array}{l}\text { População reassentada versus } \\
\text { empresa mineradora e autoridades } \\
\text { governamentais }\end{array}$ \\
\hline $\begin{array}{l}\text { Corredor de desenvolvimento de } \\
\text { Nacala (Nampula, Niassa e } \\
\text { Zambézia) }\end{array}$ & Pro-Savana & $\begin{array}{l}\text { População atingida versus } \\
\text { autoridades governamentais }\end{array}$ \\
\hline Topuito - Moma & $\begin{array}{l}\text { Megaprojeto de extração de areias } \\
\text { pesadas da Kenmare }\end{array}$ & $\begin{array}{l}\text { População reassentada versus } \\
\text { empresa mineradora e autoridades } \\
\text { governamentais }\end{array}$ \\
\hline $\begin{array}{l}\text { Namanhumbir - Montepuez (Cabo } \\
\text { Delgado) }\end{array}$ & $\begin{array}{l}\text { Megaprojeto de extração de rubis da } \\
\text { empresa Montepuez Ruby Maning }\end{array}$ & $\begin{array}{l}\text { População reassentada versus } \\
\text { empresa mineradora e autoridades } \\
\text { governamentais }\end{array}$ \\
\hline Palma - Cabo Delgado & $\begin{array}{l}\text { Megaprojeto de extração de petróleo e } \\
\text { seus derivados }\end{array}$ & $\begin{array}{l}\text { População reassentada versus } \\
\text { empresa mineradora e autoridades } \\
\text { governamentais }\end{array}$ \\
\hline
\end{tabular}

Fonte: Elaborado pelos autores com base no Relatório da Liga Moçambicana dos Direitos Humanos (2004); Mutzenberg (2013, v.14) e Chaimite (2014).

No Quadro 2, são indicados alguns casos de assassinatos, torturas e abusos das autoridades policiais que mereceram repúdio por parte da Liga Moçambicana dos Direitos Humanos (LMDH) e da sociedade em geral.

Quadro 2 - Casos de assassinatos, torturas e abusos pelas autoridades policiais

\begin{tabular}{|llll|}
\hline \multicolumn{1}{|c|}{ Designação } & \multicolumn{1}{c}{ Razão da sua ocorrência } & Local de ocorrência & Ano \\
\hline “Caso Montepuez" & $\begin{array}{l}\text { Protestos pós-eleitoriais que terminaram com a } \\
\text { detenção de 119 membros da RENAMO e } \\
\text { posterior morte por asfixia }\end{array}$ & $\begin{array}{l}\text { Montepuez - Cabo } \\
\text { Delgado }\end{array}$ & 2000 \\
\hline & $\begin{array}{l}\text { Adérito, menino de 13 anos morto por membros } \\
\text { da polícia comunitária por ter sido confundido } \\
\text { como um "menino da rua" que havia invadido }\end{array}$ & $\begin{array}{l}\text { Bairro T3, na cidade de } \\
\text { Maputo }\end{array}$ & 2003 \\
\hline
\end{tabular}




\begin{tabular}{|c|c|c|c|}
\hline “Caso Simões” & $\begin{array}{l}\text { Edson Simões, menino de } 11 \text { anos violentado pela } \\
\text { polícia comunitária sem evidências de ter } \\
\text { praticado crime. }\end{array}$ & Beira - Sofala & 2003 \\
\hline $\begin{array}{l}\text { "Caso Revolta dos } \\
\text { combustíveiss" }\end{array}$ & $\begin{array}{l}\text { Elevação do preço dos combustíveis, o que } \\
\text { motivou o aumento dos preços dos transportes e } \\
\text { dos produtos alimentícios e, consequentemente, as } \\
\text { revoltas populares que foram fortemente reprimidas } \\
\text { pela polícia }\end{array}$ & $\begin{array}{l}\text { Cidades de Maputo, } \\
\text { Matola e Beira }\end{array}$ & 2008 \\
\hline $\begin{array}{l}\text { "Caso de greve de } \\
\text { aumento de preços } \\
\text { de produtos } \\
\text { básicos" }\end{array}$ & $\begin{array}{l}\text { Aumento de preços de produtos básicos, colocando } \\
\text { em questão o poder de compra das camadas } \\
\text { desfavorecidas }\end{array}$ & $\begin{array}{l}\text { Cidades de Maputo e } \\
\text { Matola }\end{array}$ & 2010 \\
\hline $\begin{array}{l}\text { "Caso de revoltas } \\
\text { contra raptos e da } \\
\text { instabilidade } \\
\text { política" }\end{array}$ & $\begin{array}{l}\text { Revolta surgida como consequência do aumento de } \\
\text { raptos aos agentes comerciais e em virtude da } \\
\text { instabilidade política que o país vivia }\end{array}$ & Cidade de Maputo & 2013 \\
\hline $\begin{array}{l}\text { "Caso de revoltas } \\
\text { populares em } \\
\text { Moatize"” }\end{array}$ & $\begin{array}{l}\text { Disputa de espaço entre a mineradora Vale- } \\
\text { Moçambique e a comunidade de Nhanchere, na } \\
\text { vila de Moatize, que resultou na morte de um } \\
\text { cidadão da comunidade pelas autoridades } \\
\text { policiais. }\end{array}$ & Nhanchere - Moatize & 2017 \\
\hline $\begin{array}{l}\text { "Caso } \\
\text { Namanhumbire", }\end{array}$ & $\begin{array}{l}\text { Garimpeiros de minas de rubis em Namanhumbire } \\
\text { foram fortemente torturados pelas autoridades } \\
\text { policiais dentro da sua comunidade, alegadamente } \\
\text { porque praticavam de forma ilegal a atividade de } \\
\text { garimpo em prejuizo da empresa concessionária. }\end{array}$ & $\begin{array}{l}\text { Namanhumbir - } \\
\text { Montepuez }\end{array}$ & 2017 \\
\hline
\end{tabular}

Fonte: Elaborado pelos autores com base em LMDH(2004); Mutzenberg (2013); Chaimite (2014); Brito et al (2015); Lalá e Ostheimer (2004)

Massarongo (2017) indica que como consequência das manifestações populares, 0 governo passou em revista diferentes medidas com objetivo de mitigar o custo de vida das populações. Os exemplos destas medidas são os casos de subsídios de preços de alguns produtos (pão, combustíveis fósseis), tentativa de introdução de "cesta básica" para populações urbanas desfavorecidas e política monetária contra inflação da moeda, incentivo na produção de produtos alimentícios como trigo, milho, hortas, além de outros.

De concreto, Brito et al (2017) apontam que os planos governamentais de redução da pobreza e garantia da segurança alimentar traduzidos em políticas públicas são bastante numerosos, notando-se, porém, o carácter repetitivo dos mesmos e sua sobreposição o que não passa mais que uma simples listagem de intenções e com ausência de articulação entre si, fazendo com que o seu 
impacto seja nulo. Aí, a contribuição da sociedade civil é enfraquecida pela incapacidade governamental na materialização de diferentes políticas públicas tal como observaram estes autores quando descrevem que "se a ação estatal é fraca, não obstante a multiplicidade de documentos e planos existentes, a ação da sociedade civil no campo alimentar é também praticamente nula" (BRITO et al, 2017, p. 13).

Diante das precárias condições sociais e da violência explícita ao chamado "Estado democrático de direito" é que os cidadãos moçambicanos têm questionado o Estado no que diz respeito à segurança pública e à garantia dos direitos humanos. Vale lembrar que a atual Constituição da República de Moçambique, no seu preâmbulo, consagra o "[...] carácter soberano do Estado de Direito Democrático, baseado no pluralismo de expressão, organização partidária e no respeito e garantia dos direitos e liberdades fundamentais dos cidadãos" (MOÇAMBIQUE, 2004). Ademais, essa Constituição preconiza, no Art. 87, o direito à greve e a proibição de lock-out.

Para além dos dados constantes no quadro 2 do artigo, destaca-se que, como casos exemplares, faram evidenciados os seguintes dados (NOTA; AZEVEDO, 2017) obtidos num estudo realizado em 2017 que: 1. Dos 90 reclusos inquiridos na Penitenciária Provincial de Tete: 60 (66,6\%) revelaram que, para confessar no envolvimento do crime do qual foram acusados, tinham sido submetidos a coação física ou psicológica durante o interrogatório pelos policiais e apenas 30 (33,4\%) revelaram que não foram submetidos a nenhuma coação física ou psicológica; 2. Quanto aos mecanismos de coação utilizados, $50(83,3 \%)$ reclusos numa amostra de 60 revelaram que tinham sido submetidos a tortura durante a sua detenção e disseram terem sido chicoteados com cassetete e sofrido agressão física à mão e 10 (16,7\%) restantes afirmaram que tiveram os dedos apertados com alicate; 3. Estes 60 reclusos - referentes ao item 2 - fizeram-se ao interrogatório sem advogado e os 30 - referentes ao item 1 - fizeram-se ao interrogatório acompanhados de um advogado ou defensor oficioso o que revela que a falta de advogado no momento de interrogatório é motivação para os policiais praticarem torturas aos suspeitos.

Em entrevista aos policiais, o estudo inquiriu 30 agentes, sendo que $80 \%$ responderam que a tortura é ensinada no processo de formação dos policiais, ou seja, durante o treinamento. Já os recrutas são desnecessariamente punidos, maltratados e violentados pelos seus instrutores o que fica inscrito no formando como componente de instrução e a ter em conta no exercício da profissão policial. Os restantes $20 \%$ afirmaram que embora sejam sempre advertidos a respeitar a componente dos direitos humanos na sua atuação, isso fica nulo porquanto o que fica no seu imaginário é sempre a experiência passada no campo de treinos.

De acordo com Brito el al (2017), as revoltas populares urbanas registradas entre anos de 2008-2012 que no meio dos analistas sociais locais foram designadas de revoltas de fome ou de pão 


\section{VIOLÊNCIAS DO ESTADO E SEGURANÇA PÚBLICA EM MOÇAMBIQUE PÓS-INDEPENDÊNCIA}

devido ao móbil reivindicativo ${ }^{8}$ dos seus proponentes se enquadram em dois contextos: 1 . Num movimento mais amplo de dimensão global que vem afetando vários países desde 2008 derivado do aumento e de alta volatilidade dos preços de produtos alimentícios no mercado internacional e; 2. Dinâmicas econômicas e políticas internas que resultam da exclusão social e política das camadas sociais urbanas mais encarecidas.

$\mathrm{Na}$ verdade, se de um lado a conjuntura internacional marcada pela oscilação de preços de produtos de primeira necessidade (produtos alimentícios e combustíveis fósseis) afetava o País como dependente da importação de alimentos, ao nível nacional se experimentava continuamente 0 descontentamento popular devido ao agravamento das condições de vida da população.

Relativamente ao contexto interno das greves, Mondlate (2017) partilha o mesmo pensamento de Brito et al (2017) ao constatar que existem dois mecanismos críticos identificáveis na literatura moçambicana: a) a inflação muito acelerada de preços de produtos alimentícios; b) diferenças na composição da despesa dos agregados familiares. Em nossa opinião, com alguma dose na influência externa, estes fatores internos terão jogado uma cartada decisiva na eclosão das manifestações populares.

Em todas as manifestações populares de 2008-2012 existiu um denominador comum: 0 seu carácter efémero, ou seja, a sua pouca durabilidade. A duração das manifestações oscilava entre um a três dias, mas com efeitos negativos expressivos no domínio socioeconômico. Durante as manifestações populares, os insurgentes bloqueavam principais vias de acesso colocando pedras enormes, carcaças de viaturas velhas, latas de lixo entre outros objetos julgados convenientes e incendiavam pneus, saqueavam lojas apropriando-se de produtos alimentícios e queimavam viaturas (BRITO et al, 2017; CHAIMITE, 2017).

O problema que se coloca na República de Moçambique pode ser compreendido numa perspectiva de antagonismo entre o que está legislado e os modi operandi da máquina governamental. A esse respeito, Lalá e Ostheimer (2004, p.16) são tácitos em afirmar que:

Embora Moçambique possua um quadro legislativo adequado para Estado de Direito, verificam-se determinados impedimentos na sua implementação apropriada, em face de fatores históricos, culturais e institucionais existentes.

Ainda sobre essa perspectiva de antagonismo entre o que está legislado e os modi operandi da máquina governamental, Brito et al. (2015, p. 8) observaram que o poder hegemônico da FRELIMO, partido no poder desde a independência, "[...] apesar de tolerar formalmente os partidos e as estruturas formais da democracia multipartidária, [...] considera os partidos de oposição como politicamente ilegítimos", o que de fato é um atropelo aos princípios básicos da convivência 
multipartidária num Estado que se diz ser Estado de direito democrático. Outrossim, os mesmos autores constaram que o governo da FRELIMO esforça-se para esvaziar:

[...] as garantias constitucionais do direito de livre reunião e manifestação, uma vez que, na prática, se as manifestações que são direta ou indiretamente promovidas pelo partido no poder ou organizações que Ihe são próximas são aceites, já o mesmo se torna difícil quando essas iniciativas são promovidas por grupos independentes e pelos partidos da oposição. (BRITO et al., 2015, p. 8).

A questão das violências, particularmente as violências do Estado, tem merecido uma atenção especial no mundo contemporâneo. No caso da República de Moçambique, muito tem sido feito pelas Organizações não Governamentais (Liga Moçambicana dos Direitos Humanos, Associação Moçambicana das Mulheres de Carreira Jurídica entre outras entidades da sociedade civil) na intermediação de conflitos relacionados às violências do Estado entre o governo e a população. Outrossim, embora de forma muito tímida, nota-se alguma preocupação por parte do próprio governo na percepção de que a violência do Estado contra os direitos humanos, particularmente os direitos civis, políticos, sociais (SANTOS, 2009), não pode constituir como melhor caminho para solução das tensões sociais, tal como descrevem Brito, et al. (2015, p.37), quando tecem a seguinte afirmação:

Tanto em 2008 como em 2010 e 2012, os protestos populares provocaram, numa primeira fase, uma ação de repressão por parte do governo, na tentativa de os abafar. Assim, a primeira reação do governo foi de os considerar ilegais e mobilizar as forças policiais para repor a ordem pública [...].

Num outro desenvolvimento, e reconhecendo caráter hibridista das autoridades governamentais, os autores sustentam que:

Porém, perante a força de rua e a evidência - impossível de ignorar - do impacto do custo de vida nas camadas mais pobres, o governo passa em cada momento da crise de uma estratégia de confrontação a uma tentativa de acomodação através de cedências e anúncios de novas políticas (BRITO et al, 2015, p. 39).

Todavia, tais esforços ainda não são suficientes se levarmos em consideração que 0 Estado, através de alguns dos seus agentes, continua a violar os direitos humanos mais elementares dos cidadãos. Esse fato põe em causa a segurança pública das classes mais desfavorecidas e do processo de democratização da vida econômica, social e política do país. Assim, consideramos que existe uma longa distância a percorrer em matéria de respeito aos direitos humanos e para se atingir esse respeito, o que não depende apenas do governo de Moçambique, porque este está mergulhado na conjuntura da política neoliberal internacional. 


\section{VIOLÊNCIAS DO ESTADO E SEGURANÇA PÚBLICA EM MOÇAMBIQUE PÓS-INDEPENDÊNCIA}

\section{CONCLUSÃO}

O objetivo desse artigo foi tentar compreender a problemática das violências do Estado e da segurança pública. Mais especificamente analisamos sobre as violências do Estado em Moçambique pós-independência focando, principalmente, nas tensões sociais e nas respostas da máquina governamental em relação aos conflitos. Averiguamos que recorrentemente 0 Estado moçambicano, ao invés de elaborar políticas públicas participativas e democráticas, tem utilizado da prática de repressão violenta como meio para silenciar as contendas sociais surgidas como consequência do agravamento das condições de vida da população.

Tendo em conta os resultados das entrevistas realizadas por Johansson e Sambo (2017) que, na sua maioria apontam, a) subida dos preços dos produtos e serviços básicos em contraste com a estagnação dos rendimentos; b) a falta de possibilidade de ser ouvido e de influenciar a sua própria vida e c) 0 imaginário que existe entre os manifestantes de que "enquanto o sofrimento da população está a piorar, o bem estar da elite política e econômica tende a aumentar", sugerimos as seguintes estratégias de minimização tais como: 1. Redesenhamento, monitoração e avaliação dos resultados de todas as políticas estatais que foram elaboradas e que não passaram de uma simples listagem de intenções como argumentaram Brito et al (2017) e 2. Para que os insurgentes se sintam parte integrante dos processos de governação do País é necessário que essas políticas sejam redesenhadas em consonância com as comunidades. Mais que ninguém, elas saberão dar propostas de mitigação dos seus problemas e, quiçá, evitar-se-iam futuras manifestações populares desta natureza. Outrossim, é necessário reduzir o fosso entre ricos e pobres, principalmente aqueles que dominam a elite política e a grande maioria da população que ainda vive na incerteza em seu dia a dia.

A coexistência entre a violência legítima e a violência ilegítima perpetrada pelos agentes do Estado tais como agressões, repressões, desaparecimentos forçados, perseguições, torturas e assassinatos revela uma faceta cruel das políticas de corte neoliberais que passam a prevalecer já na segunda metada de década de 1980 (JOSÉ, 2005). A priorização de políticas punitivas em detrimento de políticas públicas e sociais, voltadas para responder às demandas da maioria da população, demonstra a fragilidade da democracia moçambicana e a falta de vontade política dos governantes já que, na arena política, nada têm feito para estimular e reconhecer o "pluralismo agonístico da democracia" (MOUFFE, 2005) o que, em nossa opinião, reduziria a violência ilegítima dos agentes do Estado e aproximaria as partes em conflito permanente para pensar a busca bem estar da sociedade moçambicana e consequente o fortalecimento do Estado Democrático de Direito em Moçambique. Aliás, como pontuou Mouffe (2003), a caraterística fundamental da democracia moderna reside na aceitação e reconhecimento do conflito como elemento impulsionador do desenvolvimento, não 
podendo ser eliminado "pela imposição de uma ordem autoritária", já que "uma sociedade democrática dá oportunidade para a expressão de interesses e valores conflitantes" (MOUFFE, 2003, p.17).

Finalmente, percebemos que existe ainda muito trabalho para se enfrentar as práticas de violação dos direitos humanos assim como as práticas de violências de Estado praticadas em Moçambique. Como comprendemos que parte desse problema está relacionado aos modelos de políticas construídas por meio dos "consensos" internacionais pautados nos modelos econômicos excludentes, tal enfrentamento deve ser feito em perspectiva mundial.

\section{REFERÊNCIAS}

ABRAHAMSSON, Hans; NILSSON, Anders. Moçambique em transição: um estudo da história de desenvolvimento durante o período 1974-1992. Maputo: Centro de Estudos Estratégicos e Internacionais - Instituto Superior de Relações Internacionais (CEEI-ISRI), 1994.

ALÍSSIO, Fernanda Cristina. A violência simbólica na escola: uma abordagem a partir da visão dos educandos e educadores. 2007. 108 f. Dissertação (Mestrado em Sociologia da Educação) - Centro Universitário Salesiano de São Paulo, Americana, SP, 2007. Disponível em: www.am.unisal.br/pos/stricto - educação /pdf/ . Acesso em: 16 jun. 2015.

BARBOSA, Mariana Reis. Violência do Estado: dos discursos sociais às leituras individuais. 2013. 261 f. Tese (Doutorado em Psicologia de Justiça) - Universidade de Minho, Braga, 2013. Disponível em: https://repositorium.sdum.uminho.pt/bitstream/1822/34331/1/Mariana\%20Reis\%20Barbosa.pdf. Acesso em: 14 mar. 2016.

BERTELSEN, Bøjrn Enge. Efervenscência efémera: Levantamentos populares urbanos em Moçambique. In: BRITO, Lúis de (org.). Agora Eles Têm Medo de Nós! - Uma colectânea de textos sobre as Revoltas Populares em Moçambique (2008 - 2012). Instituto de Estudos Sociais e Ecômicos (IESE): Maputo, 2017, pp. 124-152. Disponível em: www.iese.ac.mz/wp-content/uploads/2018/02/IESEFood-Riot.pdf . Acesso em: 30 maio 2018.

BORGES, Igor Vasco. A formação profissional de policiais e enfrentamento a delinquência nos marcos da edificação do Estado moçambicano (1975 - 1990). Revista do Laboratório de Estudos da Violência da UNESP/Marília. São Paulo. Ano 2012. Edição 9, mai. 2012, p.31-47. Disponível em: http://www2.marilia.unesp.br/revistas/index.php/levs/article/view/2234/1852. Acesso em: 21 nov. 2018.

BRITO, Luís de et al. Revoltas de fome: protestos populares em Moçambique (2008-2012). Cadernos IESE, Maputo, n. 14P, fev. 2015.

BRITO, Luís de. Pobreza, "parpas" e governação: Desafios para Moçambique, v. 42, 2012. Disponivel em: http://www.iese.ac.mz/lib/publication/livros/des2012/IESE_Des2012_1.PobParGov.pdf. Acesso em: 30 jan. 2018.

BRITO et al. Revoltas de fome: protestos populares em Moçambique (2008 - 2012). In: BRITO, Luís de. (org.). Agora eles têm medo de nós: Uma coletânea de textos sobre as revoltas populares em Moçambique (2008 - 2012). Maputo: Instituto de Estudos Sociais e Econômicos (IESE), 2017, p. 1 47). Disponível em: http://www.iese.ac.mz/wp-content/uploads/2018/02/IESE-Food-Riot.pdf. Acesso em 22 nov. 2018. 
CALVEIRO, Pila. Violência do Estado. Mexico: SigloXXI, 2012.

CHAIMITE, Egídio. Das revoltas às marchas: Emergência de um repertório da ação coletiva em Moçambique. In: BRITO, Luís de (org.). Agora eles têm medo de nós! - uma coletânea de textos sobre as revoltas populares em Moçambique (2008 - 2012). Maputo: Instituto de Estudos Sociais e Econômicos (IESE), 2017, p. 153 - 168). Disponível em: http://www.iese.ac.mz/wpcontent/uploads/2018/02/IESE-Food-Riot.pdf. Acesso em 22 nov. 2018.

DUARTE, Maria Carolina de Almeida; SILVA, Maria Salete Amaro da. A criminalidade violenta na sociedade contemporânea: um estudo sobre a "indústria" da cultura do medo no imaginário social.

Revista do Programa de Pós-Graduação em História da Universidade Federal de Mato Grosso, n. 2, p. 83-102, 2004.

DUMA, Custódio. Licença para matar: responsabilização da polícia em Moçambique. Maputo: Amnistia Internacional, 2008. In: Amnisty Internacional Publication. London, 2008, p. 3-22. Disponível em: https://www.amnesty.org/download/Documents/AFR410012008PORTUGUESE.PDF . Acesso em: 27 maio 2018.

EUSÉBIO, Albino José; MAGALHÃES, Sónia Barbosa. Instabilidade político-militar e a vida cotidiana em Moçambique. In: 30 Reunião Brasileira de Antropologia, 06 a 06 ago. 2016. João Pessoa/PB. Disponível em: www.30rba.abant.org.br/arquivo/downloadpublic?q . Acesso em 22 maio 2018.

FRATTARI, Najla Franco. Discursos e representações do medo da violência na cidade de Goiânia. In: SOUZA, Dalva Borges de (org.). Violência urbana em Goiás: práticas e representações. Goiânia: UFG, 2011.

HERNÁNDEZ, Héctor Guerra. Modernidade Seletiva e o Estado Predador: Primeira aproximação às revoltas populares em Moçambique de 2008 e 2010. In: BRITO, Lúis de (org.). Agora Eles Têm Medo de Nós! - Uma colectânea de textos sobre as Revoltas Populares em Moçambique (2008 - 2012). Instituto de Estudos Sociais e Ecômicos (IESE): Maputo, 2017, pp.169-194. Disponível em: www.iese.ac.mz/wp-content/uploads/2018/02/IESE-Food-Riot.pdf . Acesso em 30 maio 2018.

HUMBANE, Eduardo Moisés Jumisse. Sociedade, Escola e Cidadania. Que relações? Uma análise a partir das Escolas Secundárias de Maputo, Moçambique. 2016. 252 f. Tese ( Doutorado em Sociologia) - Prgograma de Pós-Graduação em Sociologia da Universidade Federal de Goiás (UFG), Goiás, 2016. Não publicada.

JOHANSSON, Kajsa; SAMBO Michel. As revoltas do pão: Um exercício de cidadania? In: BRITO, Luís de. (org.). Agora eles têm medo de nós! - uma coletânea de textos sobre as revoltas populares em Moçambique (2008 - 2012). Maputo: Instituto de Estudos Sociais e Econômicos (IESE), 2017, p. 87 123. Disponível em: http://www.iese.ac.mz/wp-content/uploads/2018/02/IESE-Food-Riot.pdf. Acesso em 22 nov. 2018.

JOSÉ, André Cristiano. Neoliberalismo e a crise do trabalho em Moçambique: 0 caso da indústria de Caju. 0 Cabo dos trabalhos. Centro de Estudos Sociais. Coimbra, Portugal, 2005.

LALÁ, Anícia; OSTHEIMER, Andrea E. Como limpar as nódoas do processo democrático? Os desafios da transição e democratização em Mocambique (1990-2003). Maputo: Konrad- AdenauerStiftung, 2004. 
MALOA, Joaquim Miranda. 0 lugar da desordem. Um estudo sociológico sobre 0 assalto à mão armada em Moçambique na cidade de Lichinga. 2012. 164 f. Dissertação (Mestrado em Sociologia) Programa de Pós-Graduação em Sociologia, Universidade de São Paulo, São Paulo, 2012. Disponível em: www.teses.usp.br/teses/disponiveis/8/8132/tde.../2012_JoaquimMirandaMaloa.pdf. Acesso em 29 maio. 2018.

MASSARANGO, Fernanda. Revoltas populares em Moçambique: Uma taxa de câmbio anti-riot? In: BRITO, Luís de. (org.). Agora eles têm medo de nós! - uma coletânea de textos sobre as revoltas populares em Moçambique (2008 - 2012). Maputo: Instituto de Estudos Sociais e Econômicos (IESE), 2017, p. 74 - 86. Disponível em: http://www.iese.ac.mz/wp-content/uploads/2018/02//ESE-FoodRiot.pdf. Acesso em 22 nov. 2018.

MATOS, Elmer Agostinho Carlos de; MEDEIROS, Rosa Maria Viera. Exploração mineira em Moatize, no centro de Moçambique: Que futuro para as comunidades locais? 2012. Trabalho apresentado no XXI Encontro Nacional de Geografia Agrária. "Territórios em desputa: Os desafios da Geografia Agrária nas contradições do desenvolvimento brasileiro". UFU - Minas Gerais. 15 a 19 out. 2012. Disponível em: http://www.lagea.ig.ufu.br/xx1enga/anais_enga_2012/eixos/1064_1.pdf. Acesso em: 22 maio 2018.

MOÇAMBIQUE. Centro de Integridade Pública. "Importação de combustíveis liquidos: quadro institucional, processos, riscos, perspectivas". Maputo, jun. 2016. Disponível em: https://cipmoz.org/images/Documentos/Anti-corrupcao/combustiveisliquidos.pdf. Acesso em: 18 fev. 2018.

MOÇAMBIQUE. Constituição (1975). Ementa constitucional n 1, de 25 de junho de 1975. Maputo, I série, jun. 1975.

MOÇAMBIQUE. Constituição (1990). Ementa constitucional n 44, de 22 de novembro de 1990. Dá nova redação à Constituição de 1975 monopartidária, transformando em uma Constituição multipartidária. Maputo, I série, suplemento de sexta feira, nov. 1990.

MOÇAMBIQUE. Constituição (2004). Ementa constitucional $n^{0}$ 51, de 22 de dezembro de 2004. Substitui a Constituição de 1990 para adequação de novas dinâmicas da evolução democrática em Moçambique. Maputo, I série, dez. 1990.

MONDLATE, Oksana. Revoltas da fome em Moçambique: um olhar para além dos preços internacionais. In: BRITO, Luís de (org.). Agora eles têm medo de nós! - uma coletânea de textos sobre as revoltas populares em Moçambique (2008 - 2012). Maputo: Instituto de Estudos Sociais e Econômicos (IESE), 2017, p. 48 - 73. Disponível em: http://www.iese.ac.mz/wpcontent/uploads/2018/02/IESE-Food-Riot.pdf. Acesso em 22 nov. 2018.

MOUFFE, Chantal. Dossiê democracias e autoritarismos: Por um modelo agonístico de democracia. Revista Sociologia Política, Curitiba, $n^{0}$. 25, p.11-23, nov. 2005. Disponível em: http://www.scielo.br/pdf/rsocp/n25/31108.pdf. Acesso em: 24 maio. 2018.

Democracia, cidadania e a questão do pluralismo. Revista Política e Sociedade, Florianópolis, $n^{\circ} 3$, p. 11-26, out. 2003. Disponível em: https://periodicos.ufsc.br/index.php/politica/article/viewFile/2015/1763 . Acesso em: 27 maio 2018. 
MUTZENBERG, Remo. Protestos sociais em Moçambique: uma agenda de pesquisa. Civitas - Revista de Ciências Sociais, Porto Alegre, v. 14, n. 1, p.137-153, jan.-abr. 2014. Disponível em:

revistaseletronicas.pucrs.br/ojs/index.php/civitas/article/download/16196/10965. Acesso em: 16 out. 2017.

NOTA, David Adriano; AZEVEDO, Tupinambá Pinto de. Violação dos direitos humanos por agentes da polícia no ato de investigação criminal. Revista da Faculdade de Direito da UFRGS, Porto Alegre, $\mathrm{n}$. 36, p. 55-72, ago. 2017. Disponível em: https://seer.ufrgs.br/revfacdir/article/download/72749/43552. Acesso em: 21 nov. 2018.

OFFE, Claus. Dominação de classes e sistema político: sobre a seletividade das instituições políticas. In: __ Problemas estruturais do Estado capitalista. Tradução: Bárbara Freitag. Rio de Janeiro: Tempo Brasilleiro, 1972.

PIMENTA, Carlos Alberto Máximo. A complexidade das relações societárias e os novos sujeitos: a violência como ponto de partida. Revista Ciências Humanas, n. 1, p. 17-26, 1996.

RELATÓRIO DA LIGA MOÇAMBICANA DOS DIREITOS HUMANOS. Maputo, 2004. Disponível em: http://www.iese.ac.mz/lib/PPI/IESE-

PPI/pastas/governacao/justica/artigos_cientificos_imprensa/relatorioldh2003.pdf. Acesso em: 19 jan. 2017.

SAMB, Fatime. A mulher moçambicana e as práticas culturais. In: MORAIS, Carolina Maira Gomes et al (orgs.). Encontros com Moçambique [recurso eletrônico]. Rio de Janeiro: Ed. PUC-Rio, 2016.

Disponível em: http://www.editora.vrc.puc-

rio.br/media/Encontros\%20com\%20Mo\%C3\%A7ambique\%20(e-book).pdf. Acesso em 20 nov. 2018.

SANTOS, José Vicente Tavares dos. Violências e conflitualidades. Porto Alegre: Tomo Editorial, 2009.

SPIVAK, Gayatri Chakravorty. Pode o subalterno falar? Belo Horizonte: UFMG, 2010.

TSUCANA, Fernando Francisco. Formação superior de oficiais da Polícia de Moçambique: articulação entre os fundamentos teóricos e as habilidades práticas. 2014. 315 f. Tese de doutorado apresentada ao Programa de Pós-Graduação em Educação: Currículo pela Pontifícia Universidade Católica de São Paulo. São Paulo: PUC-SP, 2014. Disponível em:

https://sapientia.pucsp.br/bitstream/handle/9778/1/Fernando\%20Francisco\%20Tsucana.pdf. Acesso em: 21 nov. 2018.

WACQUANT, Loic. Forjando o estado neoliberal: trabalho social, regime prisional e insegurança social. In: BATISTA, Vera Malaguti (org.). Loic Wacquant e a questão penal no capitalismo neoliberal. Rio de Janeiro: Revan, 2012.

WEBER, Max. Economia e sociedade: fundamentos da Sociologia compreensiva. Brasília, DF: Ed. Universidade de Brasília, 1999.

\section{Notas}

1 Em termos de localização geográfica, Moçambique fica na zona Austral e na Costa Oriental de África, junto ao Canal de Moçambique e em frente à llha de Madagascar. 
2 Entre os vários planos de recuperação da economia de Moçambique nesse período, os que impactaram profundamente no tecido social são o Programa de Reabilitação Econômica (PRE) e o Programa de Reabilitação Econômica e Social (PRES).

3 Segundo Maloa (2012, p.123), em Moçambique, "[...] muitas armas utilizadas na guerra civil não foram recolhidas pelo Estado depois de encerrarem a Operação Rachel (1995-1998), conduzido pelo governo de Moçambique e África do Sul e do Programa Transformação da Arma por Enxada (TAE), lançados em 1995 pelo Conselho Cristão de Moçambique; ambos os programas tiveram muitos sucessos na recolha de armas e desarmamento da sociedade civil, mas, apesar do avanço significativo nesta matéria, o resultado ainda é insatisfatório".

4 Os exemplos dessas novas práticas são apresentados nos Quadros 1 e 2.

5 Este acordo, conhecido mundialmente como Acordo de Roma, realizou-se nessa cidade e contou, além dos representantes do Governo e da Resistência Nacional de Moçambique (RENAMO), com uma equipe de mediadores composta, na sua maior parte, por membros da Igreja Católica.

6 CENTRO DE INTEGRIDADE PÚBLICA. "Importação de combustíveis liquidos: quadro institucional, processos, riscos, perspectivas". Maputo, jun. 2016. Disponível em: https://cipmoz.org/images/Documentos/Anticorrupcao/combustiveisliquidos.pdf. Acesso em: 18 fev. 2018.

7 Os exemplos desses megaprojetos são os casos de carvão mineral em Tete; areias pesadas em Moma; pedras preciosas e semipreciosas em Namanhimbir e gás natural em Palma.

8 Os sujeitos dessas revoltas eram indivíduos das classes desfavorecidas do meio urbano e os fatores motivadores são o custo elevado de transporte público, o sentimento cada vez mais crescente de desigualdades sociais entre a elite política e a grande maioria esmagadora da população moçambicana, a corrupção e aumento dos produtos alimentícios (BRITO et al, 2017). 